\title{
The Molecular Basis of an Inhibition by Tetracyclines
}

\author{
By J. E. BENBOUGH* AND G. A. MORRISON \\ The Edward Davies Chemical Laboratory, Aberystwyth, Cardiganshire
}

(Accepted for publication 23 June 1967)

\begin{abstract}
SUMMARY
The pyruvate-consuming system of Aerobacter aerogenes, which is inhibited by bacteriostatic concentrations of tetracyclines in an unaerated mineral salt medium, was isolated as a cell-free extract. The isolated system was inhibited by bacteriostatic concentrations of eight tetracyclines. The inhibitory molecular form of each of these tetracyclines, all of which were acids releasing either two or three protons successively in aqueous solution, was the first dissociation product. Quantitatively the inhibition was directly dependent on the concentration of the inhibitory form of the antibiotic present. The tetracyclines tested were derived structurally from tetracycline by changes of the group attached at position 5, 6 or 7 (type $a$ ), a de-(dimethylamino) tetracycline (type $b$ ) and anhydrotetracycline. None of the tetracyclines was inhibitory in the absence of free magnesium ions. In the presence of micromolar concentrations of these ions, the inhibitory form of the tetracycline competed with flavine mononucleotide: the effectiveness of different tetracyclines as inhibitors of unaerated cultures correlated with the stability constants of postulated tetracycline-magnesium-enzyme complexes. The intracellular concentrations of tetracyclines in organisms of sensitive and resistant strains were determined by measurements of inhibition of the pyruvate-consuming system. In medium containing bacteriostatic concentrations of types $a$ and $b$ tetracyclines, the intracellular concentrations of the sensitive organisms were the same as the extracellular concentrations. Anhydrotetracycline did not penetrate these organisms so readily. One of the resistant strains was insensitive because the tetracyclines did not penetrate into the organisms. There were no intracellular accumulations of tetracyclines from medium containing bacteriostatic concentrations. The bearing of these results on current theories to account for the bacteriostatic actions of tetracyclines is discussed.
\end{abstract}

\section{INTRODUCTION}

Tetracyclines inhibit a considerable number of metabolic reactions (Eagle \& Saz, 1955; Snell \& Cheng, I962; Franklin, 1966) and three main theories have been advanced to account for their bacteriostatic actions. (I) It has been suggested that the ability of tetracyclines to combine with essential metallic cations is the cause of their biological effects (Albert, 1953; Albert \& Rees, 1956). Although some tetracyclines, which have the ability to form co-ordination compounds with cations, have no antibacterial activity (Weinberg, I957), some of the effective tetracyclines combine with fused ring compounds of biological importance such as riboflavin, adenylic acid and deoxyribonucleic acid (Higuchi \& Bolton, 1959) and there is a cationic bridge between the macromolecules of deoxyribonucleic acid and the tetracyclines. Serum albumin combines similarly with tetracyclines (Kohn, I96r). (2) Saz \& Martinez (I958) suggested that the antibiotic action of chlortetracycline on Escherichia coli is due to

* Present address: Microbiological Research Establishment, Porton, Nr. Salisbury, Wiltshire. 
an inhibition of the electron transport system. Decreases of the rates of growth due to the presence of tetracyclines have been associated with interferences with oxidationreduction processes in Aerobacter aerogenes (Jones \& Morrison, 1962; Benbough \& Morrison, 1965) and Staphylococcus 209E (Plakunov, 1963 $b$; 1964). (3) Franklin (1963) attributed the antibiotic action on $E$. coli to inhibition of the incorporation of amino acids into ribosomal protein, and the relative efficiencies of five tetracyclines as inhibitors of polyphenylalanine synthesis can be correlated with their efficiencies as antibiotics (Laskin \& Chan, 1964).

Snell \& Cheng (1962) considered that tetracyclines can inhibit many reactions and that the problem is to determine the order of importance as a function of increasing concentration. If this be so then the reaction which is most sensitive may not be the same for all microbial species or for a given species under different experimental conditions. Many of the arguments for and against particular theories have been based on comparisons of the concentration of the tetracycline that was effective against the isolated system and the growing organism. However, the tetracyclines are acids which not only ionize in aqueous solution, releasing successively either two or three protons, but also form complexes with divalent cations such as magnesium. Hence the total concentration of tetracycline present is distributed between a number of chemically distinct molecular forms in equilibrium with each other. From the data normally available in reports it is not possible to identify the particular molecular form which is inhibitory, nor to calculate the actual concentrations of the various forms. It has also been suggested that sensitive organisms possess an active transport mechanism for tetracyclines which produces an intracellular accumulation of these antibiotics (Franklin \& Godfrey, 1965). Clearly arguments based on total concentrations may therefore be misleading.

The decrease of the rate of growth of a strain of Aerobacter aerogenes in a glucose mineral salt medium with tetracycline has been studied quantitatively (Jones \& Morrison, 1962; Benbough \& Morrison, 1965). Inhibitions of rate of growth were expressed as the 'index ratios' (Harris \& Morrison, I96I)-that is, the mean generation time of the inhibited culture when in its logarithmic phase divided by the mean generation time of the corresponding uninhibited culture. This is more useful mathematically than the ' $\%$ inhibition'. At concentrations of inhibitor greater than the threshold concentration, the index ratio became linearly dependent on the concentration of inhibitor provided that the retardation of the rate of growth stemmed from interference with the same metabolic reaction throughout the range of concentration considered. The rate of change of the index ratio with respect to change of concentration of the inhibitory tetracycline was characteristic of the particular tetracycline and of the inhibited reaction. When the primary cause of the retardation of growth changed from interference with one metabolic reaction to another, within the studied range of concentration of a particular tetracycline, there was an abrupt alteration of the rate of change of the index ratio from the value characteristic for the one reaction to that characteristic of the new rate-controlling reaction. For convenience each vulnerable metabolic reaction was referred to as a 'mode' and the modes were distinguished from each other by assigning numerals.

Oxytetracycline had two different modes of action: mode I was attributed to interference with the utilization of amino acids by aerated cultures, and mode 2 to interference with a hydrogen transfer reaction or the production of a hydrogen acceptor 
required for unaerated growth (Jones \& Morrison, 1962). The rate of consumption of pyruvate by non-multiplying organisms in the absence of aeration, but not when the medium was aerated, was inhibited (Jones \& Morrison, 1963). Korotyaev (1962) reported similar results for a strain of Escherichia coli. The effectivenesses of six different tetracyclines as inhibitors of pyruvate consumption by Aerobacter aerogenes were directly and quantitatively related to their effectivenesses as inhibitors of growth by mode 2 , and consequently these retardations of pyruvate consumption were considered to arise from inhibition by mode 2 (Benbough \& Morrison, 1965). The 7-chlor substituted tetracyclines inhibited aerated growth more severely (mode 3 ) but the presence of D-glutamate in the medium eliminated this mode whilst permitting inhibition by mode $\mathrm{I}$. The 7 -chlor substituted tetracyclines and tetracycline itself, at the lowest bacteriostatic concentrations, inhibited the rate of growth of unaerated cultures by mode I, but at higher concentrations by mode 2. 6-demethyl-6-deoxytetracycline inhibited the rates of growth of both aerated and unaerated cultures by mode I, but weakly inhibited the consumption of pyruvate by non-multiplying organisms in unaerated medium by mode 2 . Since the presence in the medium of $0.2 \%(\mathrm{w} / \mathrm{v})$ brilliant cresyl blue or methylene blue eliminated all three modes of action, each mode had to be attributed to interference with an electron transfer reaction.

Inhibition by each mode was related quantitatively, and linearly, to the concentration in the medium of the product of the first dissociation of the tetracycline, whether this was altered by varying the total concentration of the tetracycline, varying the $\mathrm{pH}$ value of the medium or by varying the concentration of magnesium ions. The inhibition could not be related directly to the concentration of any other of the molecular forms of a tetracycline. Thus either the first dissociation products are the inhibitors of the primary sites or are the only molecular forms able to penetrate into the organisms. The rate of change of index ratio with respect to change of concentration of the inhibitory molecular form of a tetracycline, 'the intrinsic activity' (Benbough \& Morrison, 1965), was used as a measure of the maximal effectiveness of the tetracycline as an inhibitor by a particular mode.

The present work examines the inhibition by tetracyclines of the isolated pyruvateconsuming system of Aerobacter aerogenes NCTC4I8 in order to establish which molecular form of a tetracycline inhibits the primary site responsible for mode 2 , to identify more closely the affected site and to investigate the mechanism of the inhibition. Comparisons of the effectivenesses of tetracyclines as inhibitors of the isolated system and of the system whilst in its normal place in the organisms, are used to provide direct evidence of the concentrations of the inhibitory form within the organisms. The eight tetracyclines studied include seven variations in the side groupings and anhydrotetracycline.

\section{METHODS}

Organism, media and cultivation techniques. The organism used was Aerobacter aerogenes, strain NCTC4I8, which had been maintained for twelve years by regular subcultivation at $37^{\circ}$, with and without aeration, in a basal medium containing (g./1.): $5.4, \mathrm{KH}_{2} \mathrm{PO}_{4}$; I 2, glucose; $\mathrm{I} \cdot 8,\left(\mathrm{NH}_{4}\right)_{2} \mathrm{SO}_{4} ; 0.0203, \mathrm{MgSO}_{4} \cdot 7 \mathrm{H}_{2} \mathrm{O}$ (all Analar) in demineralized water of resistance greater than $2 \mathrm{M} \Omega / \mathrm{cm}$., adjusted to $\mathrm{pH} 7.00$ (Radiometer type PHM 4 C, V. A. Howe and Co. Ltd., 46, Pembridge Road, London, W. I I) with $\mathrm{NaOH}$. Other media were prepared by making the appropriate additions or 
omissions of materials. The preparation of inocula, measurements of rate of growth, preparation of solutions of pyruvic acid from pure lithium pyruvate and measurements of concentration of pyruvate were as described previously (Jones \& Morrison, I962; Jones \& Morrison, I963; Benbough \& Morrison, 1965).

Resistant substrains of the organism. Six subcultures in unaerated basal medium initially at $\mathrm{pH} 7.00$ containing $(a) 0.2 \mu \mathrm{M}$ tetracycline and $(b)$ brilliant cresyl blue $20 \mathrm{mg} . / \mathrm{ml}$. (Benbough \& Morrison, 1965) produced substrains A and B respectively. The rates of growth of both substrains were unaffected by concentrations of tetracycline sufficient to treble the mean generation time in cultures of the parent strain (index ratio of $3 \cdot 0$ ).

Preparation of suspensions of bacteria and of cell-free extracts. Bacteria were obtained from fully grown unaerated cultures in medium containing (g./1.): $\mathrm{I} \cdot 08$, glucose; $0 \cdot \mathrm{I}_{5},\left(\mathrm{NH}_{4}\right)_{2} \mathrm{SO}_{4}$; with the usual concentrations of $\mathrm{KH}_{2} \mathrm{PO}_{4}$ and $\mathrm{MgSO}_{4} \cdot 7 \mathrm{H}_{2} \mathrm{O}$, adjusted to $\mathrm{pH} 7 \cdot 00$. When the growth amounted to two-thirds of the maximum obtainable in normal medium, the glucose had been consumed completely and only about $0.14 \mathrm{mM}$-ammonium ion remained. Suspensions of unwashed bacteria were obtained by suspending them in enough of the culture liquid to give equiv. $0.5 \mathrm{mg}$. dry wt bacteria/ml. Suspensions of washed bacteria were obtained by suspending an equivalent amount of bacteria washed in $\mathrm{KH}_{2} \mathrm{PO}_{4} 9^{\circ} 0 \mathrm{~g} . / 1$. buffer $\left(\mathrm{pH} 7^{\circ} .00\right)$ in the equivalent volume of appropriately buffered solution. Freshly prepared suspensions were used for each set of experiments after incubation at $37^{\circ}$ for $\mathrm{I} \mathrm{hr}$.

Suspensions prepared as above were treated at $0^{\circ}$ in a $60 \mathrm{~W}$ M.S.E. ultrasonic disintegrator to bursts of $15 \mathrm{sec}$. duration in each of 20 successive minutes. This killed almost all the bacteria but there was no serious loss of ability to consume pyruvate. The debris was removed by centrifugation at $3000 \mathrm{~g}$ and the extract incubated for I hr at $37^{\circ}$ before use, to consume metabolities in it.

Measurements of inhibition and inhibitory power. Inhibitions of rates of growth of culture are expressed as the index ratios, and the effectiveness of a tetracycline as an inhibitor by a particular mode by the intrinsic activity. As the equilibria between the different molecular forms of anhydrotetracycline are greatly affected by small changes of $\mathrm{pH}$ value, and growing cultures changed their $\mathrm{pH}$ values progressively, the growth curves (log equiv. mg. dry wt bacteria/ml. plotted against time) of cultures inhibited by anhydrotetracycline were markedly sigmoid in shape. The index ratios for cultures inhibited by anhydrotetracycline were obtained from the maximum rates of growth, and the intrinsic activities from these values and the concentrations of the inhibitory molecular form (calculated from the total concentrations of anhydrotetracycline and the hydrogen ion concentration prevailing at the times of maximum rates of growth).

Inhibitions of the rate of consumption of pyruvate are expressed as the reciprocal of the 'fractional activity' (Hunter \& Downs, 1945), which corresponds to the index ratio. The experimental data were obtained by analysis of $3 \mathrm{ml}$. samples withdrawn at suitable intervals from $20 \mathrm{ml}$. of appropriately buffered solution containing $5 \mathrm{ml}$. of freshly prepared suspension of bacteria or of cell-free extract, $0.8-1 \mathrm{~mm}$ pyruvate, and test substances. After 5-10 min. the progress curves were linear and the ratios were calculated from the slopes of the linear portions.

Determination of dissociation constants of tetracyclines and the stability constants of their complexes with $\mathrm{Mg}^{2+}$. These constants were calculated from the results of potentiometric titrations (Monk, I96I). 
Antibiotics used. Six of the tetracyclines were given by Charles Pfizer Ltd. and the 7-chlorotetracyclines by Lederle Laboratories Ltd. The nomenclature used is essentially that of Benbough \& Morrison (1965): $\mathrm{TH}_{3}{ }^{+} \mathrm{Cl}^{-}$denotes a tetracycline hydrochloride and $\mathbf{T H}_{2}$ the 4-de(dimethylamino)-6-demethyl-6-deoxytetracycline which does not form a hydrochloride. The dissociation constants, the stability constants of the complexes with $\mathrm{Mg}^{2+}$ and the intrinsic activities as inhibitors of growth have been listed previously for six of the tetracyclines (Jones \& Morrison, 1962; Benbough \& Morrison, 1965). The corresponding data for anhydrotetracycline and the 4-de(dimethylamino)tetracycline are given in Table $\mathrm{I}$. The first dissociation products, $\mathrm{TH}_{2}$ and $\mathbf{T} \mathbf{H}^{-}$, are the molecular forms inhibitory to growing cultures and to the pyruvate consumption by unaerated suspensions, and the complexes with $\mathrm{Mg}^{2+}$ are $\mathrm{THMg}^{+}$and $\mathrm{THMg}^{+}$.

The concentration of the first dissociation product of a tetracycline is given by $C_{t} / \Sigma$, where $C_{t}$ is the total concentration of the tetracycline (all molecular forms taken together) and

$$
\Sigma=\left[\mathrm{H}^{+}\right] / K_{1}+\mathrm{I}+K_{2} /\left[\mathrm{H}^{+}\right]+K_{2} K_{3} /\left[\mathrm{H}^{+}\right]^{2}+K_{2} K_{\text {stab }}\left[\mathrm{Mg}^{2+}\right] /\left[\mathrm{H}^{+}\right]
$$

for tetracyclines with three dissociation constants, and

$$
\Sigma=\left[\mathrm{H}^{+}\right] / K_{1}+\mathrm{I}+K_{2} /\left[\mathrm{H}^{+}\right]+K_{\text {stab }}\left[\mathrm{Mg}^{2+}\right]
$$

for the de(dimethylamino)tetracycline. $K_{\text {stab }}$ is the stability constant of the magnesiumtetracycline complex. $\left[\mathrm{Mg}^{2+}\right]$, the concentration of free magnesium ions, was calculated from the total concentration by allowing for association with phosphate and sulphate ions in the medium (Jones \& Morrison, 1962). The importance of these calculations is illustrated by the facts that whereas $88 \%$ of a concentration of tetracycline is in the form $\mathrm{TH}_{2}$ at $\mathrm{pH} 7.00$ and $54 \%$ at $\mathrm{pH} 7 \cdot 80$, the corresponding figures for anhydrotetracycline are $15 \%$ and $2.6 \%$ respectively.

Table I. Anhydrotetracycline and 4-de(dimethylamino)-6-demethyl-6deoxytetracycline $\left(\mathrm{T} \mathrm{H}_{2}\right)$

The intrinsic activity is the change of index ratio per $\mathrm{m} \mu \mathrm{M}$ of the first dissociation product of the tetracycline (which is the inhibitory molecular form) measured in the basal growth medium. The index ratio is the mean generation time of the inhibited culture divided by the mean generation time of the corresponding uninhibited culture. The intrinsicactivities of other

\begin{tabular}{|c|c|c|c|c|}
\hline \multirow[b]{2}{*}{ Tetracycline } & \multirow[b]{2}{*}{$\begin{array}{l}\text { Dissociation } \\
\text { constants } \\
(p \mathrm{~K})\end{array}$} & \multirow{2}{*}{$\begin{array}{c}\text { Stability } \\
\text { constant of } \\
\text { of } \mathrm{Mg} \text { complex } \\
\left(\log K_{\mathrm{stab}}\right)\end{array}$} & \multicolumn{2}{|c|}{$\begin{array}{l}\text { Intrinsic activity as } \\
\text { inhibitors of growth }\end{array}$} \\
\hline & & & $\begin{array}{r}\text { Mode I } \\
\text { (aerated) }\end{array}$ & $\begin{array}{c}\text { Mode } 2 \\
\text { (unaerated) }\end{array}$ \\
\hline Anhydro- & $\left.\begin{array}{l}3.4 \\
6 \cdot 3 \\
8 \cdot 7\end{array}\right\}$ & $4 \cdot 0$ & 0.0018 & 0.0044 \\
\hline $\mathrm{TH}_{2}$ & $\left.\begin{array}{l}5 \cdot 8 \\
8 \cdot 5\end{array}\right\}$ & $2 \cdot 8$ & 0.00015 & 0.00035 \\
\hline
\end{tabular}
tetracyclines are given in Benbough \& Morrison (1965; Table 5).

RESULTS

Inhibition of pyruvate consumption by cell-free extracts

For each tetracycline in turn, the inhibitions of pyruvate consumption by cell-free extracts (made from suspensions of washed Aerobacter aerogenes organisms) were determined over a range of concentration of the antibiotic in media containing (g./1.): 
$4 \cdot 45, \mathrm{KH}_{2} \mathrm{PO}_{4} ; 0.0203, \mathrm{MgSO}_{4} \cdot 7 \mathrm{H}_{2} \mathrm{O}$; adjusted to $\mathrm{pH} 6 \cdot 20-7 \cdot 80$ with $\mathrm{NaOH}$; and in media containing (g./1.): $4.45, \mathrm{KH}_{2} \mathrm{PO}_{4} ; 0.0203-0.203, \mathrm{MgSO}_{4} \cdot 7 \mathrm{H}_{2} \mathrm{O}$; adjusted to $\mathrm{pH} 7 \cdot 00$. The concentrations of $\mathrm{Mg}^{2+}$ calculated by the method of Jones \& Morrison (I962) ranged from $16 \cdot 4$ to $\mathrm{I} 64 \mu \mathrm{M}$. For each tetracycline above its threshold concentration, the ratio of the uninhibited rate to the inhibited rate was related linearly to the concentration of the first dissociation product of the tetracycline, $\mathrm{TH}_{2}$ or $\mathbf{T H}^{-}$, irrespective of whether this was being varied by changing the total concentration of antibiotic, changing the $\mathrm{pH}$ value of the medium or changing the concentration of $\mathrm{Mg}^{2+}$. Thus the molecular forms $\mathrm{TH}_{2}$ and $\mathrm{TH}^{-}$were the inhibitors of the isolated system.

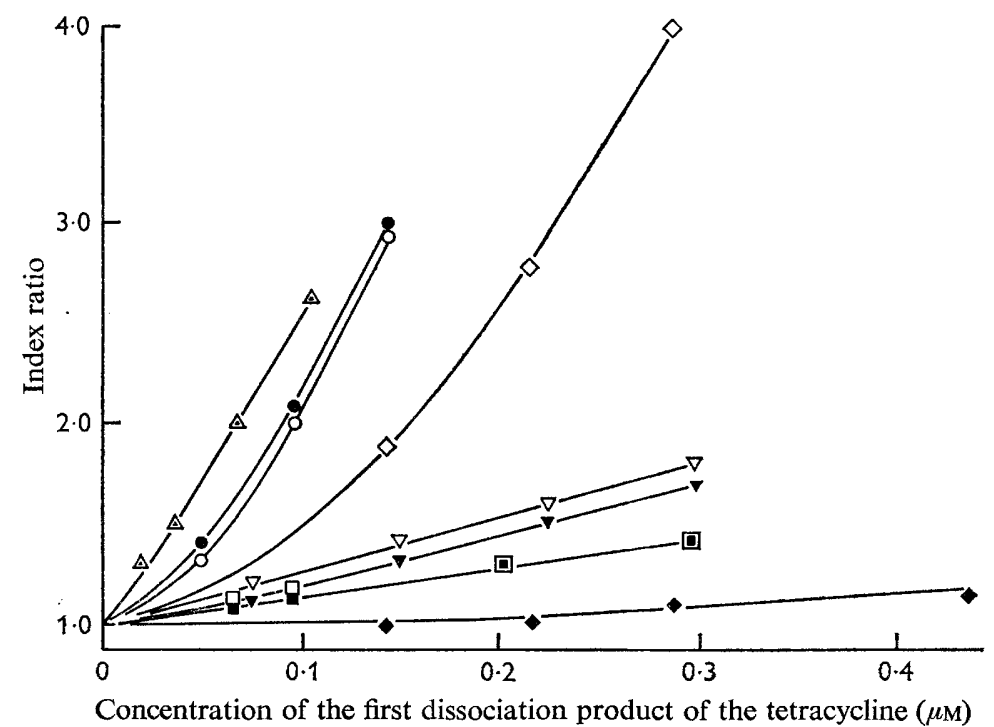

Fig. I. Inhibition by tetracyclines of the consumption of pyruvate by suspensions and cellfree extracts of Aerobacter aerogenes NCTC $4 \mathrm{I} 8$ in medium containing: (g./I.) $4.45, \mathrm{KH}_{2} \mathrm{PO}_{4}$; $0.0203, \mathrm{MgSO}_{4} .7 \mathrm{H}_{2} \mathrm{O} ; 0.0704$, pyruvic acid initially; adjusted to $\mathrm{pH} 7.00$ with $\mathrm{NaOH}$. Measurements of rates of reaction described under Methods. The solid points show the results with suspensions of bacteria (equiv. $0.125 \mathrm{mg}$ dry wt/ml.) and the open points the results with cell-free extracts prepared from the same suspensions. $\Delta, \Delta$, Chlortetracycline; , $O$, methylene-oxytetracycline; $\boldsymbol{\nabla}, \nabla$, tetracycline; $\boldsymbol{\square}, \square$, demethyl-deoxytetracycline; $\diamond, \diamond$, anhydrotetracycline. Index ratio is the rate of the uninhibited reaction divided by the rate $f$ the inhibited reaction.

\section{Comparisons of inhibitions of whole organism suspensions and of cell-free extracts}

Part of a suspension of unwashed organisms was reserved whilst the rest was treated to produce a cell-free extract. The inhibitions of pyruvate utilization by various concentrations of one of the tetracyclines were measured for each preparation. The results for five tetracyclines are shown in Fig. I. The slopes of the linear portions of these graphs (change of index ratio per $\mu \mathrm{M}$ change of concentration of the first dissociation product of the antibiotic; results for suspensions given first) were: 7 -chlortetracycline, I6.0, I6.0; 6-methylene-oxytetracycline, I6.9, I7. I ; tetracycline, $3 \cdot 7,4^{\cdot 0}$; 6-demethyl-6-deoxytetracycline, I.45, I.45; anhydrotetracycline, 0.95, I6.6; (not illustrated) 6-demethyl-7-chlortetracycline, $20 \cdot 4,22 \cdot 0$; oxytetracycline, 2.3, 2.3; 
4-de(dimethylamino)-6-demethyl-6-deoxytetracycline, $0.27,0.30$. Thus in seven cases the tetracycline was $I \cdot O-I \cdot I$ times as effective against the isolated system as it was against whole organisms under the same conditions. Anhydrotetracycline, however, was 17.5 times as effective against the isolated system. The system, when part of whole organisms, was protected from anhydrotetracycline but not from the other compounds. This suggests that the system was inside the organisms and that, of the eight tetracyclines examined, all but anhydrotetracycline penetrated readily so that the intracellular concentration of the inhibitory form of the antibiotic was essentially that of the medium. This finding could help to explain why anhydrotetracycline is as effective as other tetracyclines against actinomycetes but not against most other micro-organisms (Goodman, Matrishin \& Backus, I955): actinomycetes will grow in slightly acid media which would increase the proportion of the anhydrotetracycline in the form of the first dissociation product to more nearly that of other tetracyclines, and it may penetrate the actinomycetes more readily than it does other microorganisms.

Table 2. Lipids of Aerobacter aerogenes NCTC 418 and substrains $A$ and $B$

Data from Dr A. M. James, Department of Chemistry, Queen Elizabeth College, London. The bacteria were grown in aerated medium containing (g./ I.): $5.4, \mathrm{KH}_{2} \mathrm{PO}_{4} ; \mathrm{I} \cdot 8\left(\mathrm{NH}_{4}\right)_{2} \mathrm{SO}_{4}$; $\mathrm{I} \cdot 08$, glucose; harvested and washed with distilled water; dried and extracted with $\mathrm{CHCl}_{3}+$ $\mathrm{CH}_{3} \mathrm{OH}$. The extract was washed free from water-soluble material, dried and methylated. The analysis was by gas chromatography. For details see Hill, James \& Maxted (1963).

\begin{tabular}{ccccc} 
Chromato- & \multicolumn{3}{c}{ mg. methyl ester obtained from I g. dry intact } \\
gram peak & Ester & NCTC418 & Substrain A & Substrain B \\
A & Laurate & 0.014 & 0.036 & trace \\
B & Myristate & 0.088 & 0.089 & 0.017 \\
C & $?$ & 0.018 & 0.018 & 0.017 \\
D & Palmitate & 0.810 & 0.930 & 0.279 \\
E & Oleate & 0.510 & 0.466 & 0.161 \\
F & $?$ & 0.037 & 0.018 & - \\
G & $?$ & Trace & - & - \\
H & $?$ & 0.386 & 0.613 & 0.100 \\
I & $?$ & 0.159 & 0.219 & 0.034 \\
J & Stearate & Trace & 0.018 & Trace \\
K & $?$ & 0.306 & 0.358 & 0.034 \\
L & $?$ & 0.194 & 0.174 & 0.017 \\
M & $?$ & 0.124 & 0.210 & - \\
N & $?$ & 0.107 & 0.141 & - \\
& Total & 2.76 & 3.32 & 0.66
\end{tabular}

Examination of the two resistant substrains of Aerobacter aerogenes confirmed this suggestion. None of the tetracyclines at concentrations that inhibited severely the parent strain $A$. aerogenes NCTC $4 \mathrm{I} 8$, affected the consumption of pyruvate by intact organisms of either substrain. The system isolated from substrain A (obtained by subcultivation in presence of tetracycline) was exactly as sensitive to the antibiotics as the system isolated from the parent strain; but that isolated from the substrain $B$ (obtained by subcultivation in presence of brilliant cresyl blue) was not sensitive. The resistance of substrain $A$ was due to the development of impermeability to the tetracycline whereas that of substrain B arose from the development of independence from any sensitive reaction. Franklin \& Godfrey (1965) and Laskin \& Chan (1964) reported cases in which systems isolated from resistant Escherichia coli organisms were just as 
sensitive as the systems isolated from sensitive organisms, but these systems could not be tested directly whilst in their normal positions in the organisms. A nitroreductase from an aureomycin-resistant $E$. coli was also resistant, although that from aureomycinsensitive organisms was not (Saz, Brownell \& Slie, 1956). The resistant nitroreductase bound flavine mononucleotide firmly, whereas the corresponding complex with the enzyme from sensitive organisms was readily dissociable (Saz \& Martinez, 1956). Plakunov ( $1963 a)$ reported that the major change in metabolism of a tetracycline resistant strain of Staphylococcus aureus was an increase of flavine mononucleotide to 4.5 times the normal value.

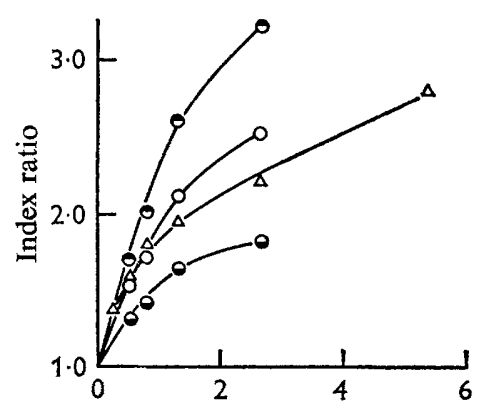

Concentration of free $\mathrm{Mg}^{2+} ;(\mu \mathrm{M})$

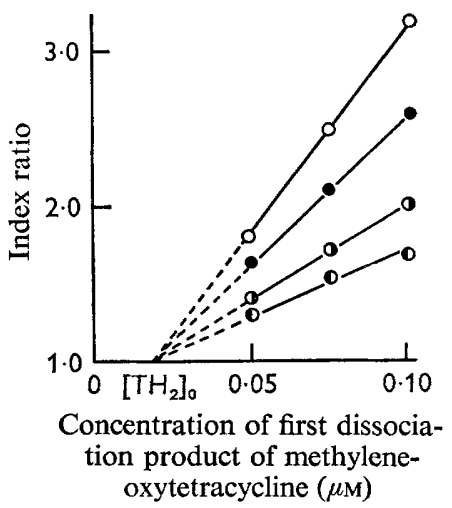

Fig. 3

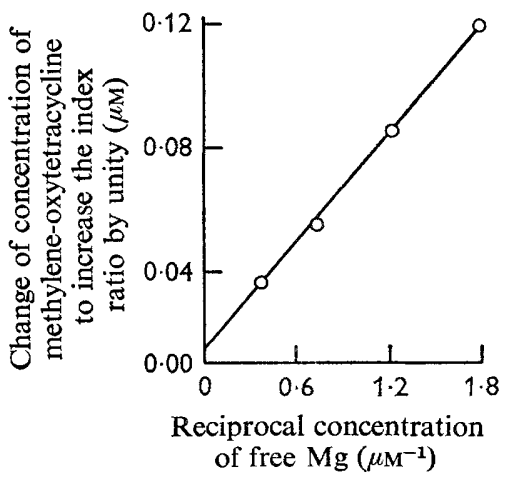

Fig. 4

Fig. 2

Figs. 2, 3, 4. Magnesium and inhibition by tetracyclines of the consumption of pyruvate by dialysed cell-free extracts of the Aerobacter aerogenes NCTC 4 I 8 (equivalent to suspensions of $0.125 \mathrm{mg}$. dry wt bacteria/ml.) in medium containing: (g./1.) 2.25, $\mathrm{KH}_{2} \mathrm{PO}_{4} ; 0.0704$, pyruvic acid initially; adjusted to $\mathrm{pH} 7.00$ with $\mathrm{NaOH}$. Measurement of rates as under Methods; concentrations of free magnesium ion by method of Jones \& Morrison (1962). Index ratio is the rate of the uninhibited reaction divided by the rate of the inhibited reaction. Fig. 2. Dependence of inhibition on concentration of free magnesium ion. Concentration of the first dissociation product of the tetracycline $(\mu \mathrm{M})$ : demethyl-chlortetracycline, $0.084, \triangle$; methyleneoxytetracycline, $0.0506, \ominus ; 0.0760,0 ; 0.1013$, $\ominus$. Fig. 3. Dependence of inhibition on concentration of thefirst dissociation product of methylene-oxytetracycline. Concentration of free magnesium ion $(\mu \mathrm{M}): 0.56,0 ; 0.82,0 ; 1 \cdot 36,0 ; 2 \cdot 72,0$. Fig. 4 . Relation between slopes of linear portions of graphs in Fig. 3 and the concentration of free magnesium ion for inhibitions by methylene-oxytetracycline.

The possible differences of permeability of the parent strain and substrain A may be connected with the increased content of lipid of the cell walls of some tetracyclineresistant bacteria obtained from clinical sources noticed by Hill, James \& Maxted (1963). The analyses of the lipids extracted from Aerobacter aerogenes NCTC 4I 8 and from the substrains A and B are given in Table 2 (Dr A. M. James, personal communication).

\section{Magnesium and inhibition of cell-free extracts}

Dialysis of cell-free extracts of Aerobacter aerogenes NCTC4I 8 against demineralized water (specific conductance $0.5 \times 10^{-6}$ reciprocal $\Omega$ ) slowly and progressively decreased their abilities to consume pyruvate, and decreased more rapidly their sensitivities to tetracyclines. After $\mathrm{I} 8 \mathrm{hr}$ the residual rates of consumption of pyruvate were un- 
affected by usually inhibitory concentrations of a tetracycline, but the sensitivity was restored by $\mathrm{I}-\mathrm{IO} \mu \mathrm{M}$ free magnesium ion. Such low concentrations of $\mathrm{Mg}^{2+}$ have a negligible effect on the proportion of a tetracycline which is in the inhibitory form. This general dependence of inhibition by tetracyclines on the presence of $\mathrm{Mg}^{2+}$ is illustrated in Fig. 2 by results for 6-demethyl-7-chlorotetracycline and 6-methyleneoxytetracycline. Figure 3 shows that for each given concentration of $\mathrm{Mg}^{2+}$ the inhibition by the methylene-oxytetracycline became directly proportional to the concentration of the first dissociation product of the tetracycline, i.e. index ratio $=\mathrm{I}+B\left\{\left[\mathrm{TH}_{2}\right]-\right.$ $\left.\left[\mathrm{TH}_{2}\right]_{0}\right\}$, where $\left[\mathrm{TH}_{2}\right]_{0}$ is a constant, but the proportionality constant $B$ was a function of the concentration of available $\mathrm{Mg}^{2+}$ ions. Figure 4 shows that experimentally I $/ B=C+D /\left[\mathrm{Mg}^{2+}\right]$, where $C$ and $D$ are constants and hence

$$
B=\left[\mathrm{Mg}^{2+}\right] /\left(C\left[\mathrm{Mg}^{2+}\right]+D\right) \text {. }
$$

At a relatively high concentration of $\mathrm{Mg}^{2+}$ the effectiveness of a tetracycline becomes independent of the concentration of $\mathrm{Mg}^{2+}$, i.e. the function of $\left[\mathrm{Mg}^{2+}\right]$ becomes equal to unity and hence the equation for $B$ must be rewritten as $\left.B=\alpha\left[\mathrm{Mg}^{2+}\right] /\left[\mathrm{Mg}^{2+}\right]+K_{\gamma}\right)$, where $\alpha$ and $K_{\gamma}$ are constants, to give the overall equation

$$
\text { index ratio }=\mathrm{I}+\frac{\alpha\left[\mathrm{Mg}^{2+}\right]}{\left(\left[\mathrm{Mg}^{2+}\right]+K_{\gamma}\right)}\left\{\left[\mathrm{TH}_{2}\right]-\left[\mathrm{TH}_{2}\right]_{0}\right\} \text {. }
$$

$\left[\mathrm{TH}_{2}\right]_{0}$ is the threshold concentration.

From the slope and the intercept with the vertical axis of the graph in Fig. 4 $K_{\gamma}=4 \cdot 3 \mu \mathrm{M}$. The shape of the function of concentration of magnesium suggests that either $\mathrm{Mg}^{2+}$ forms a complex with an enzyme (stability constant $\mathrm{I} / K_{\gamma}$ ), which then combines further with the tetracycline to form an inactive enzyme-magnesiumtetracycline complex, or the magnesium combines primarily with the tetracycline and then with the enzyme. The latter theory can be discarded since potentiometric titration of the tetracycline in the presence of $\mathrm{Mg}^{2+}$ detected only one such complex and its stability constant was only $\mathrm{I} / 280$ of $\mathrm{I} / K_{\gamma}$.

\section{Antagonists of the inhibition}

As it is known that yeast extract contains an antagonist to this inhibition by tetracyclines (or some substance from which an antagonist is produced) and that certain redox dyes also annul this inhibition (Jones \& Morrison, 1962; Benbough \& Morrison, I965), substances of suitable redox potential which occur in yeast extract were tested for antagonism. Riboflavin in the range of concentration $0-40 \mu \mathrm{M}$ progressively and markedly decreased the inhibition of cell-free extracts due to a normally bacteriostatic concentration of one of the tetracyclines, but flavine adenine dinucleotide (FAD) at higher concentrations had no effect. Incubation of the dialysed cell-free extract with riboflavin before the addition of pyruvate and tetracycline increased the effect. Foster \& Pittillo (1953) found that riboflavin annulled an inhibition by chlorotetracycline. A sample of flavine mononucleotide (FMN), prepared by hydrolysis of $F A D$, decreased the inhibition over a lower range of concentration than did riboflavin, and incubation of the system with FMN did not increase the effect. As an illustration of a general finding, Table 3 presents the results for inhibition by 6-demethyl-6deoxytetracycline. 
Table 3. Effects of riboflavin and flavine mononucleotide on inhibition by 6-demethyl-6deoxytetracycline of pyruvate consumption by dialysed cell-free extracts of Aerobacter aerogenes NCTC 418 .

The index ratio is the rate of the uninhibited reaction divided by the rate of the inhibited reaction. The extracts were equivalent to suspensions containing equiv. $0.125 \mathrm{mg}$. dry wt bacteria/ml. in medium containing $\mathrm{KH}_{2} \mathrm{PO}_{4} 2.25 \mathrm{~g}$. $/ 1 . ; 0.56 \mu \mathrm{M}$ free magnesium ion; adjusted to $\mathrm{pH} 7.00$ with $\mathrm{NaOH}$. Measurements of rate described under Methods.

\begin{tabular}{|c|c|c|}
\hline \multirow[b]{2}{*}{$\begin{array}{l}\text { Concentration of } \\
\text { co-factor }\left(\mu_{\mathrm{M}}\right)\end{array}$} & \multicolumn{2}{|c|}{ Index ratio } \\
\hline & $\begin{array}{l}\text { Antibiotic and } \\
\text { co-factor added } \\
\text { together }\end{array}$ & $\begin{array}{l}\text { Extract and co-factor } \\
\text { preincubated together }\end{array}$ \\
\hline \multicolumn{3}{|l|}{ Riboflavin } \\
\hline 0.00 & $2 \cdot 0$ & $2 \cdot 0$ \\
\hline $6 \cdot 67$ & I.95 & $I \cdot 4$ \\
\hline $13 \cdot 33$ & $r \cdot 75$ & $\mathrm{I} \cdot \mathrm{I} 5$ \\
\hline 26.67 & $1 \cdot 5$ & $I \cdot I$ \\
\hline $40 \cdot 00$ & $1 \cdot 3$ & $I \cdot 0$ \\
\hline \multicolumn{3}{|c|}{ Flavine mononucleotide } \\
\hline 0.00 & $2 \cdot 0$ & $2 \cdot 0$ \\
\hline 0.90 & $\mathrm{I} \cdot 8$ & $\mathrm{I} \cdot 8$ \\
\hline$I \cdot 80$ & $1 \cdot 4$ & $\mathrm{I} \cdot 4$ \\
\hline $2 \cdot 70$ & $I \cdot 4$ & $1 \cdot 4$ \\
\hline $3 \cdot 60$ & $I \cdot 3$ & $I \cdot 3$ \\
\hline $4 \cdot 50$ & $1 \cdot 2$ & $\mathrm{I} \cdot 2$ \\
\hline $5 \cdot 40$ & $I \cdot 15$ & $I \cdot 15$ \\
\hline
\end{tabular}

\section{DISCUSSION}

Tetracyclines inhibit the consumption of pyruvate by Aerobacter aerogenes in nearly anaerobic conditions and the primary site of the inhibition is either an electron transfer or a step in the provision of an essential hydrogen acceptor (Jones \& Morrison, I963). The present work indicates that the primary site of inhibition is a reaction which requires flavine mononucleotide (FMN) and that the tetracycline competes with FMN provided the enzyme is already combined with $\mathrm{Mg}^{2+}$. Combination between enzyme and $\mathrm{Mg}^{2+}$ alone does not affect the activity of the enzyme. As the concentration of the tetracycline is increased the fraction of the total enzyme complexed with it increases, the rate of utilization of the normal substrate decreases and hence the concentration of this substrate increases. This must compensate partially for the loss of active enzyme by causing a more efficient use of the remaining active enzyme. Eventually this ability to compensate must be exhausted and at greater concentrations of antibiotic all available enzyme molecules are saturated with substrate. The concentration of a co-factor such as FMN does not increase as readily since other reactions, in particular those that replenish it from its reduced form tend to maintain its normal concentration. The reaction becomes the rate-controlling reaction of the system and experimental kinetic data for the system apply to it. A kinetic model (Fig. 5) for this situation, therefore, may be proposed.

Equations for the rates of formation of all complexes containing enzyme can be written and equated to zero when the enzyme level steady state pertains (Briggs \& Haldane, 1925). The expression for the rate, $v$, of the reaction in the presence of excess 
substrate in terms of the reaction velocity constants and the concentrations of $\mathrm{Co}$, $\mathrm{TH}_{2}$ and $\mathrm{Mg}^{2+}$, obtained by algebraical manipulation of the equations, is

where

$$
v=\frac{K_{\delta}}{\left\{K_{\delta}+\frac{\left[\mathrm{Mg}^{2+}\right]}{\left[\mathrm{Mg}^{2+}\right]+K_{\gamma}} \frac{K_{M}}{\left([\mathrm{Co}]+K_{M}\right)}\left[\mathrm{TH}_{2}\right]\right\}}\left\{\frac{k}{\left.[\mathrm{Co}]+K_{M}\right\}}[\mathrm{En}]\right. \text {, }
$$

and

$$
K_{\gamma}=j_{1} / j_{-1}, K_{\delta}=j_{-2} / j_{2}, k=\frac{k_{2} k_{3}}{k_{2}+k_{-2}+k_{3}}
$$

$$
K_{M}=\frac{k_{-1} k_{-2}+k_{-1} k_{3}+k_{2} k_{3}}{k_{1}\left(k_{2}+k_{-2}+k_{3}\right)} .
$$

The details of the derivation of equation (2), and of the subsequent equations (3) and (4), are available in the library of the Edward Davies Chemical Laboratory.

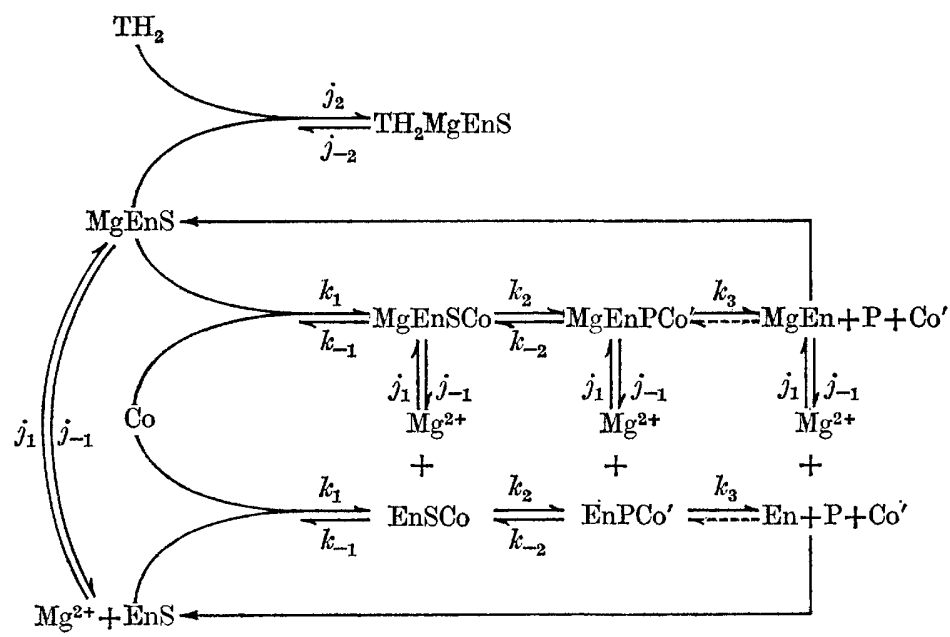

Fig. 5. Kinetic model of the inhibition of the electron transport mechanism of Aerobacter aerogenes. En represents free enzyme; S, the substrate; Co, flavine mononucleotide; $\mathrm{Co}^{\prime}$, reduced flavine mononucleotide; $\mathrm{P}$, the product. The reaction velocity constants $j_{1} \rightarrow j_{2}$ and $k_{1} \rightarrow k_{3}$ are as shown. $\mathrm{TH}_{2} \mathrm{MgEnS}$ is the inactive enzyme complex, EnS and MgEnS are active enzyme complexes.

A simpler model in which MgEnSCO and EnSCO are considered to break down directly to $\mathrm{MgEn}, \mathrm{P}$ and $\mathrm{Co}^{\prime}$, and $\mathrm{En}, \mathrm{P}$ and $\mathrm{Co}^{\prime}$, respectively, gives the same formal result, except that the composite constants $k$ and $K_{M}$ are equal to $k_{2}$ and $\left(k_{-1}+k_{2}\right) / k_{1}$ respectively.

It follows that if $v_{0}$ is the rate of the uninhibited reaction in the presence of excess substrate that

$$
v_{0} / v=\mathrm{I}+\frac{\left[\mathrm{Mg}^{2+}\right] K_{M}}{K_{\delta}\left(\left[\mathrm{Mg}^{2+}\right]+K_{\gamma}\right)\left([\mathrm{Co}]+K_{M}\right)}\left[\mathrm{TH}_{2}\right] .
$$

$v_{0}$ cannot be determined directly as in the absence of inhibitor the reaction may not be rate controlling for the system, and hence, until the concentration of the inhibitor is considerable, the substrate may not saturate the enzyme. However, in a particular experiment the rate of the uninhibited system, $v_{u}$ is directly related to $v_{0}$, i.e. $v_{u} / v_{0}=\beta$. 
Thus the index ratio, $v_{u} / v$, should give a linear plot against $\left[\mathrm{TH}_{2}\right]$ when $\left[\mathrm{TH}_{2}\right]$ is sufficiently large to cause an excess concentration of substrate. Fig. 3 shows that this was realised experimentally. $\beta$ can be calculated from the intercept with the index ratio axis, of the extrapolation of the linear portion of the plot. When $\left[\mathrm{Mg}^{2+}\right]$ is large compared with $K_{\gamma}$, as for the measurements in Table I and Fig. I, the function of $\left[\mathrm{Mg}^{2+}\right]$ is unity and the slopes of the linear plots are equal to

$$
\frac{K_{M}}{K_{\delta}} \frac{\beta}{[\mathrm{Co}]+K_{M}} \text {. }
$$

The concentration of flavine mononucleotide, Co, is unknown and therefore it is not possible to calculate the individual values of $K_{M} / K_{\delta}$ for each tetracycline. However, provided the conditions are constant, the relative values of $\mathrm{I} / K_{\delta}$ can be determined from a comparison of the slopes of the individual plots. In Fig. 6 these relative values obtained from the results for cell-free extracts are compared with the relative intrinsic activities of the tetracyclines as inhibitors of growth by mode 2 (Benbough \& Morrison, 1965, table 5; present report Table I). The effectivenesses of tetracyclines as inhibitors of growth of Aerobacter aerogenes NCTC $4 \mathrm{I} 8$ by mode 2 reflect the calculated stability constants $\left(\mathrm{I} / K_{\delta}\right)$ of the postulated tetracycline-magnesium-enzyme complexes.

It follows further from equation (3) that

$$
\frac{v / v_{0}}{\mathrm{I}-\left(v / v_{0}\right)} \quad \frac{\left[\mathrm{Mg}^{2+}\right]}{\left[\mathrm{Mg}^{2+}\right]+K_{\gamma}} \quad\left[\mathrm{TH}_{2}\right]=K_{\delta}+\frac{K_{\delta}}{K_{M}}[\mathrm{Co}]
$$

which is equivalent to the Hunter \& Downs (I945) test for competitive inhibition. Figure 7 shows that the results for the annullment by flavine mononucleotide (FMN) of inhibition of cell-free extracts by 6-demethyl-6-deoxytetracycline (Table 3) fits this equation. $v_{0}$ was calculated from $v_{u}$ and the relationship between inhibition of the same preparation and concentration of inhibitor (preceding paragraph); $K_{\gamma}$ was derived earlier from Fig. 4. The concentrations of FMN and its reduced form are unknown and hence it is not possible to calculate $K_{\delta}$ and $K_{M} . K_{M} / K_{\delta}$ is approximately O.OI.

The three main variations of structure of tetracyclines are illustrated by 6-demethyl6-deoxytetracycline, anhydrotetracycline and 4-de(dimethylamino)-6-demethyl-6deoxytetracycline in aqueous acidic solution (Fig. 8). Stephens, Murai, Brunings \& Woodward (1956) assigned the dissociations of the 4-dimethylamino-tetracyclines to the systems A, B and C in that order, but the results of experiments by Leeson, Krueger \& Nash (1963) and Kalnis \& Belenski (1964) require the order to be A, C and $\mathrm{B}$. The present results are in accord with the latter. It is likely that the forms of the three types which are inhibitory have a close structural resemblance, i.e. the products of the first dissociations of all three types should resemble each other. The common loss of a first proton from part A must increase the electron density of the oxygens at $\mathrm{C}_{\mathrm{I}}$ and $\mathrm{C}_{3}$ and thus may render one of these oxygen atoms capable of forming a magnesium bridge with the affected enzyme. Though not essential, the substituted amino group at $\mathrm{C}_{4}$ (probably with a positive charge) clearly increases the ability to combine with the enzyme and this is supported by the fact that the epi-tetracyclines are even less effective than the 4-de(dimethylamine) compounds (McCormick, Jensen, Miller \& Doersch, I960). The products of the second dissociation of anhydrotetracycline and of the demethyl-deoxytetracycline are not inhibitory. If this were due merely to the loss of a second proton from part $\mathrm{B}$, then the first dissociation product of the 
de(dimethylamino)-tetracycline, in which the whole group is missing, would also be expected to be non-inhibitory; but this was not so. However, the loss of a second proton might be from part $\mathrm{C}$ in all three cases. Conover (1956) concluded that in the potentiometrically detectable oxytetracycline-magnesium complex the magnesium is attached to the oxygens at $\mathrm{C}$ I I and $\mathrm{C}_{\mathrm{I}}$. The loss of a second proton from part $\mathrm{C}$ (probably from the hydroxyl at $\mathrm{C}$ io) would increase the electron density of the oxygen at $\mathrm{CII}_{\mathrm{I}}$, and thus combination of magnesium and the $\mathrm{C}_{\mathrm{II}}$ and $\mathrm{C}_{\mathrm{I}} 2$ oxygens is likely for the second dissociation products: in the case of anhydrotetracycline the hydrogen of the hydroxyl at C I I bonding with the negatively charged oxygen at $\mathrm{Cro}$, and in the ordinary tetracyclines the hydrogen of the hydroxyl at $\mathrm{C}_{12} 2$ bonding with the oxygen

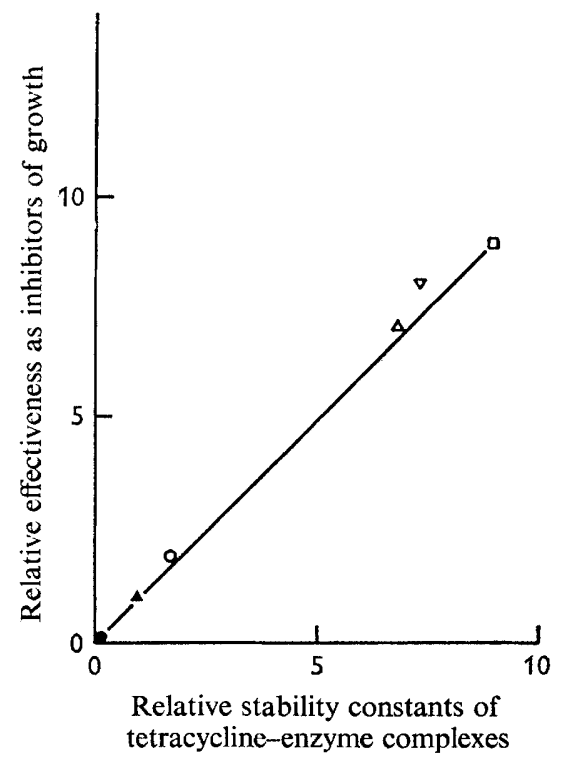

Fig. 6

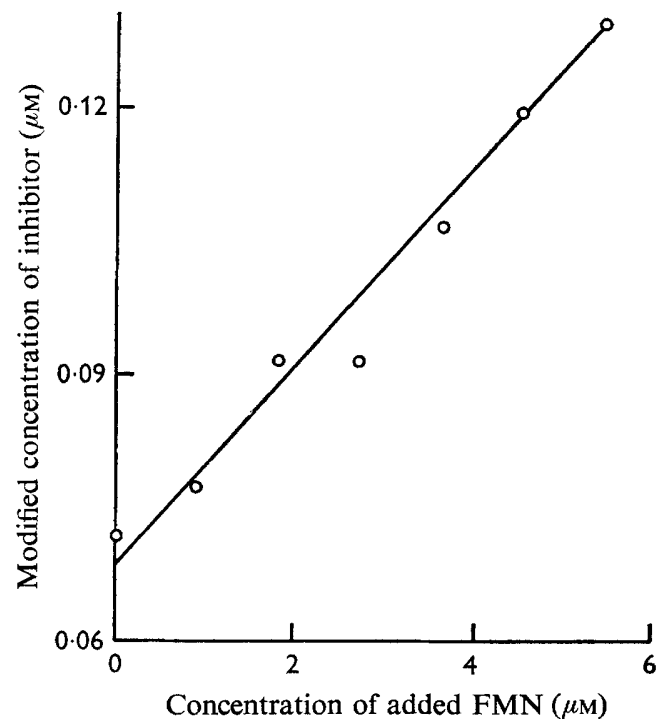

Fig. 7

Fig. 6. Comparisons of the relative effectivenesses of different tetracyclines as inhibitors of unaerated growth of Aerobacter aerogenes (in medium containing, g./1.: 5.4, $\mathrm{KH}_{2} \mathrm{PO}_{4} ; \mathrm{I} \cdot 8$, $\left(\mathrm{NH}_{4}\right)_{2} \mathrm{SO}_{4} ; \mathrm{I} 2$, glucose; $0.0203 \mathrm{MgSO}_{4} .7 \mathrm{H}_{2} \mathrm{O}$; adjusted to $\mathrm{pH} 7.00$ with $\left.\mathrm{NaOH}\right)$ and the relative stability constants of complexes between the tetracyclines and the enzyme controlling the rate of pyruvate consumption by cell-free extracts of $A$. aerogenes (in medium containing (g./1.): $5 \cdot 4, \mathrm{KH}_{2} \mathrm{PO}_{4} ; 0.0203 \mathrm{MgSO}_{4} \cdot 7 \mathrm{H}_{2} \mathrm{O}$; adjusted to $\mathrm{pH} 7.00$ with $\mathrm{NaOH}$ ). Measurements of rates described under Methods. Growth data from Table I and Benbough \& Morrison (1965, Table 5). Values for oxytetracycline taken as unity. 0 , 4-de(dimethylamino)-6-demethyl-6-deoxytetracycline; $\Delta$, oxytetracycline; $O$, tetracycline; $\Delta$, chlortetracycline; $\nabla$, methylene-oxytetracycline; $\square, 6$-demethyl-chlortetracycline.

Fig. 7. Competition between the first dissociation product of demethyl-deoxytetracycline and flavine mononucleotide (FMN) for the enzyme controlling the rate of consumption of pyruvate by dialysed cell-free extracts of Aerobacter aerogenes NCTC $4 \mathrm{I} 8$ in medium containing (g./1.): $2 \cdot 25, \mathrm{KH}_{2} \mathrm{PO}_{4} ; 0.000772, \mathrm{MgSO}_{4} .7 \mathrm{H}_{2} \mathrm{O} ; 0.0704$, pyruvic acid; adjusted to $\mathrm{pH} 7.00$ with $\mathrm{NaOH}$. $\left[\mathrm{TH}_{2}\right]$ represents the concentration of the first dissociation product of the antibiotic, $\left[\mathrm{Mg}^{2+}\right]$ the concentration of free magnesium ion $(0.56 \mu \mathrm{M}), K_{\gamma}$ the dissociation constant of the magnesium-enzyme complex $(4 \cdot 3 \mu \mathrm{M}), v$ the rate of the inhibited reaction and $v_{0}$ the maximum rate of the uninhibited reaction. The modified concentration of inhibitor is

See equation (4) in text.

$$
\frac{\nu / \nu_{0}}{\mathrm{I}-\left(\nu / \nu_{0}\right)} \frac{\left[\mathrm{Mg}^{2+}\right]}{\left[\mathrm{Mg}^{2+}\right]+K_{\gamma}} \quad\left[\mathrm{TH}_{2}\right] .
$$


at $\mathrm{C}$. The first dissociation product of the de-(dimethylamino)-tetracycline has an overall negative charge and hence a greater electron density on the oxygen at $C_{\text {I I }}$ than have the first dissociation products of the other tetracyclines. Apparently this is sufficient for bonding to magnesium ions. It is noteworthy that the stability constants for the complexes with the other tetracyclines are from I4-I40 times that of the de-(dimethylamino)-tetracycline complex, and that potentiometric titrations indicated a continuation of complex formation at high $\mathrm{pH}$ values when the form $\mathbf{T}^{2}-$ forms a considerable proportion of the total concentration of the de-dimethylamino tetracycline.<smiles></smiles>

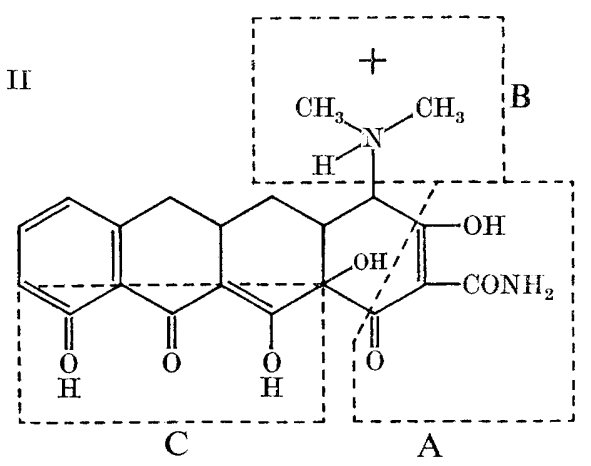<smiles>CC1c2cccc(O)c2C(O)=C2C(=O)C3(O)C(=O)C(C(N)=O)=C(O)C([NH+](C)C)C3CC21</smiles>
IV<smiles>NC(=O)C12CC1CC1CC3Cc4cccc(O)c4C(=O)C3=C(O)C1(O)C2=O</smiles>

Fig. 8. Structures of some tetracyclines in aqueous acidic solution. I, Tetracycline; II, 6-demethyl-6-deoxytetracycline; III, anhydrotetracycline; IV, 4-de(dimethylamino)-6demethyl-6-deoxytetracycline.

A similar mechanism to that suggested for mode 2 may be concerned with mode I (Jones \& Morrison, I962) and mode 3 (Benbough \& Morrison, 1965) inhibitions of the growth of Aerobacter aerogenes which are also eliminated when the medium contains an appropriate redox dye (Benbough \& Morrison, 1965). Each mode may arise from inhibition of a different FMN-requiring enzyme. The values of $K_{\delta}$ and $K_{M}$ would be likely to differ from enzyme to enzyme, but the different tetracyclines would be expected to show the same general trend of effectiveness as inhibitors by the three modes as was found by Benbough \& Morrison (1965). Similarly, since enzymes performing the same function in different organisms may not be identical in all chemical properties, and the relative importance of a function may also vary from organism to organism, the effectiveness of a mode may vary from organism to organism. One resistant strain of the $A$. aerogenes, substrain $\mathrm{B}$, was resistant because the tetracyclines were ineffective at the enzyme level. Another cause of variation between organisms is a difference in abilities of a tetracycline to penetrate into the bacteria. The other 
resistant substrain A, resisted penetration by the antibiotics and its organisms had greater lipid contents. The importance of this was shown by anhydrotetracycline which inhibited $A$. aerogenes relatively poorly because it does not penetrate the bacteria readily. The effect of this inability was enhanced by the fact that only a small fraction of the total concentration of anhydrotetracycline was in the inhibitory form in the range of $\mathrm{pH}$ values at which the organism grew. The mechanism may also be applicable in principle to other inhibitions that have been reported. Catalytic surfaces containing bound magnesium ions, or on which magnesium ions are absorbed, could complex with one or other of the anionic forms of a tetracycline that are present in solution. Detailed examination of the possibility depends upon knowledge of which form of the tetracycline is the inhibitor of the affected reaction; the data required for determining this are not yet available. There is clear evidence that multiplying organisms of sensitive strains, e.g. Escherichia coli (Franklin \& Godfrey, 1965), bind tetracyclines to their cellular material whereas organisms of resistant strains do so less readily. Only that part of the bound tetracycline which is attached to the active site of the catalyst for the rate-controlling reaction can be expected to inhibit the system. The results of the present experiments with A. aerogenes require that the intracellular concentration of the inhibitory form of the tetracycline is essentially the same as its concentration in the medium, and in this instance at least, there is no enhanced intracellular concentration of the actual inhibitor. The impermeability to tetracyclines of organisms of one resistant substrain would prevent both inhibition of the crucial reaction and binding of a tetracycline to other cellular material.

The concentrations of inhibitors (first dissociation products) needed to decrease the rate of growth of sensitive Aerobacter aerogenes NCTC $4 \mathrm{I} 8$ by $90 \%$ (by mode 2) are $(\mu \mathrm{M})$ : tetracycline, 0.6 ; oxytetracycline, $\mathrm{I} \cdot \mathrm{I}$; methylene-oxytetracycline, $0 . \mathrm{I} 4$; and demethyl-chlortetracycline, $0 \cdot 13$. The total concentrations of these tetracyclines in the blood of patients during treatment vary between $(\mu \mathrm{M}) \mathrm{I} \cdot 8$ and $9 ; \mathrm{I}$ and $5 ; 0.8$ and 6; and $\mathrm{r}$ and 6, respectively (Dr G. M. Williamson, Charles Pfizer Ltd., personal communication). Even though a high proportion of the tetracyclines in the blood may be in non-inhibitory forms because of dispersion between the different dissociation products and binding to divalent cations and serum constituents, bacterial strains as sensitive to mode 2 as is $A$. aerogenes NCTC 418 would be vulnerable under clinical conditions. Mode 3 is rather more severe than mode 2 which is somewhat more severe than mode I. Cultures of Escherichia coli ATCC I I2299/198 also were just as sensitive to tetracycline as were those of the $A$. aerogenes (G. A. Morrison, unpublished). It is noteworthy that $400 \mu \mathrm{M}$-chlortetracycline was needed to inhibit by $89 \%$ the incorporation of leucine by ribosomes from E. coli (Franklin, 1963), and that the anaerobic utilization of pyruvate by a strain of $E$. coli was sensitive to tetracyclines (Korotyaev, 1962).

We thank Mrs E. Jones and Mrs H. Griffiths for technical assistance, the Science Research Council and Charles Pfizer Ltd., for financial assistance, and Professor H. J. King and Dr P. E. Jones for constructive criticisms of the text. One of us (J.E. B.) was supported by a Thomas and Elizabeth Williams Scholarship from the County of Carmarthen. 


\section{REFERENCES}

Albert, A. (1953). The avidity of terramycin and aureomycin for metallic cations. Nature, Lond. I72, 201 .

AlberT, A. \& Rees, C. W. (1956). Avidity of the tetracyclines for metallic cations. Nature, Lond. 177, 433.

Benbough, J. E. \& Morrison, G. A. (I965). Bacteriostatic actions of some tetracyclines. J. Pharm. Pharmacol. 17, 409.

Briggs, G. E. \& Haldane, J. B. S. (I925). A note on the kinetics of enzyme action. Biochem. J. r9, 338.

Conover, L. H. (1956). Oxytetracycline and related compounds. Chem. Soc., spec. Publ. no. 5, p. 62.

Eagle, H. \& SaZ, A. K. (1955). Antibiotics. A. Rev. Microbiol. 9, 192.

FRANKLIN, T. J. (1963). The inhibition of incorporation of leucine into protein of cell-free systems from rat liver and Escherichia coli by chlortetracycline. Biochem. J. 87, 449.

FrankLin, T. J. (1966). Mode of action of the tetracyclines. Symp. Soc. gen. Microbiol. 16, 192.

Franklin, T. J. \& Godfrey, A. (1965). Resistance of Escherichia coli to tetracyclines. Biochem. J. 94, 54 .

Foster, J. W. \& PitTillo, R. F. (I953). Metabolic reversal of antibiotic inhibition, especially reversal of aureomycin inhibition by riboflavin. J. Bact. 66, 478.

Goodman, J. J., Matrishin, M. \& Backus, E. J. (I955). The effect of anhydrotetracycline on the growth of actinomycetes. J. Bact. 69, 70.

HARRIS, M. \& Morrison, G. A. (I96I). Multiple inhibitions of cell metabolism by a single substance. Nature, Lond. xgr, 1276.

Hill, M., JAMES, A. M. \& MAXTED, W. R. (1963). Some physical investigations of the behaviour of bacterial surfaces. X. The occurrence of lipid in the streptococcal cell wall. Biochim. biophys. Acta 75, 714.

Higuchi, T. \& Bolton, S. (I959). The solubility and complexing properties of oxytetracycline and tetracycline. III. Interactions in aqueous solutions with model compounds, biochemicals, chelates and hexametaphosphate. J. Am. Pharm. Assoc. Sci. 48, 557.

Hunter, A. \& Downs, C. E. (1945). The inhibition of arginase by amino acids. J. biol. Chem. 157, 427.

JONES, J. G. \& MORRISON, G. A. (I962). The bacteriostatic actions of tetracycline and oxytetracycline. J. Pharm. Pharmacol. 14, 808.

Jones, J. G. \& Morrison, G. A. (1963) Inhibition by tetracycline and oxytetracycline of the consumption of pyruvate by Aerobacter aerogenes. J. Pharm. Pharmacol. 15, 34.

KaLNIS, K. \& BELENSKI, B. G. (I964). A study of dissociation of tetracyclines by infra-red spectroscopy. Dokl. Akad. Nauk SSSR r57, 619. (in Russian)

KoHN, K. W. (I96I). Mediation of divalent metal ions in the binding of tetracyclines to macromolecules. Nature, Lond. 19I, I156.

KoROTYAEV, A. I. (1962). Effect of antibiotics on pyruvate consumption by Escherichia coli resting cells. Mikrobiologiya 3r, 24. (in Russian)

Laskin, A. I. \& Chan, M. (1964). Inhibition by tetracyclines of polyuridylic acid directed phenylalanine incorporation in Escherichia coli cell free systems. Biochem. biophys. Res. Comm. 14, 137.

Leeson, L. J., Krueger, J. E. \& NASH, R. A. (1963). Concerning the structural assignment of the second and third acidity constants of the tetracycline antibiotics. Tetrahedron Lett., no. 18 , p. 115 .

McCormick, J. R. D., Jensen, E. R., Miller, D. A. \& DoersCh, A. P. (I960). The 6-deoxytetracyclines; further studies on the relationship between structure and antibacterial activity in the tetracycline series. J. Am. chem. Soc. 82, 338I.

MonK, C. B. (196I). Electrolytic Dissociation, chap 9. London and New York: Academic Press.

Plakunov, V. K. (1963a). Biochemical changes in metabolism of Staphylococcus aureus concomitant with resistance to tetracyclines. Dokl. Akad. Nauk SSSR 151, 952. (in Russian)

Plakunov, V. K. (I963 $b$ ). Correlation of structure and mechanism of activity in the series of tetracycline antibiotics. Dokl. Akad. Nauk SSSR 151, 1207. (in Russian)

Plakunov, V. K. (1964). Mechanism of tetracycline action on Staphylococcus aureus 209P. Microbiologiya 33, 337. (in Russian) 
SAZ, A. K. \& MARTinez, L. M. (1956). Enzymatic basis of resistance to aureomycin. I. Difference between flavoprotein nitroreductase of sensitive and resistant Escherichia coli. J. biol. Chem. 223, 285.

SAZ, A. K. \& MARTinez, L. M. (1958). Enzymatic basis of resistance to aureomycin. II. Inhibition of electron transport in Escherichia coli. J. biol. Chem. 233, I020.

Saz, A. K., Brownell, L. W. \& Seli, R. N. (I956). Aureomycin-resistant cell-free nitro-reductase from aureomycin-resistant Escherichia coli. J. Bact. 7r, 421.

Snell, J. F. \& Cheng, L. (1962). Developments in Industrial Microbiology, vol. iI, p. 107. New York: Plenum Press Inc.

Stephens, C. R., Murai, K., Brunings, K. J. \& Woodward, R. B. (1956). Acidity constants of tetracycline antibiotics. $J$. Am. chem. Soc. 78, 4155 .

Weinberg, E. D. (1957). The mutual effects of antimicrobial compounds and metallic cations. Bact. Rev. 2r, 46. 